P01.02 A REGIONAL SEXUAL AND REPRODUCTIVE HEALTH CAMPAIGN PROVIDING CLINICAL EDUCATION AND HEALTH PROMOTION ACTIVITIES IN 2015 FOR ABORIGINAL HEALTH SERVICES AND COMMUNITIES IN THE WESTERN DISTRICT OF VICTORIA

${ }^{1,2} \mathrm{~B}$ Whitton* ${ }^{*},{ }^{1} \mathrm{R}$ Kinsey, ${ }^{1} \mathrm{~N}$ Waretini, ${ }^{3} \mathrm{~W}$ Toppin, ${ }^{3} \mathrm{M}$ Connelly, ${ }^{4} \mathrm{~K}$ Byron, ${ }^{4} \mathrm{~T}$ OnusWilliams, ${ }^{5} \mathrm{~A}$ Steele. ${ }^{1}$ Wulumperi Unit, Melbourne Sexual Health Centre; ${ }^{2}$ School of Population Health, University of Melbourne; ${ }^{3}$ Dhuawurd Wurrung Elderly and Community Health Service; ${ }^{4}$ Victorian Aboriginal Community Controlled Health Organisation; ${ }^{5}$ Family Planning Victoria

\subsection{6/sextrans-2015-052270.213}

Introduction Providing sexual and reproductive health services for Aboriginal communities in regional Victoria can be a challenge. High rates of Chlamydia, Hepatitis C and unplanned pregnancies are a concern for communities. Victorian Aboriginal Health Services (AHS) partner with state based specialist organisations to assist with clinical education of the AHS workforce and the communities' health promotion needs. A partnership between the Dhauwurd Wurrung Elderly and Community Health Service (DWECH) in Portland, Victorian Aboriginal Community Controlled Health Organisation (VACCHO), Wulumperi Unit Melbourne Sexual Health Centre (MSHC) and Family Planning Victoria (FPV) strives to address these ongoing needs in 2015.

Methods Clinical education was organised by DWECH for four AHS in the region and was delivered by MSHC and FPV at DWECH. Participants were Nurses and Aboriginal Health Workers from DWECH (Portland), Gunditjmara Aboriginal Cooperative (Warrnambool), Kirrae Community Health Service (Framlingham) and Windamara Aboriginal Cooperative (Heywood). The aim of the education was to increase workforce capacity by educating local AHS staff about clinical sexual and reproductive health topics and available health promotion resources.

Results The Deadly Sexy Heath Kit (health promotion resource for AHS staff) developed by VACCHO and health promotion programs developed by MSHC (Young Peoples Sexual and Reproductive Health, Sacred Sistas, Deadly Dudes) were delivered in the region to Aboriginal Communities. The individual AHS in the region will monitor their client attendance and service delivery over the 2015 period. It is expected that the AHS will see an increase in screening for Chlamydia and Hepatitis C and sexual and reproductive health awareness as a result of the health promotion activities delivered to the communities.

Conclusion Ongoing clinical sexual and reproductive health education and support of the AHS workforce and targeted health promotion programs will improve the sexual and reproductive health needs of the Aboriginal communities living in the western district of Victoria.

Disclosure of interest statement Nil.

\section{P01.03 ENCOURAGING ABORIGINAL GAY MEN TO TEST FOR HIV}

B Mackie*, M Sparks. ACON

10.1136/sextrans-2015-052270.214

Introduction ACON has commenced development of a campaign to encourage Aboriginal gay men and other homosexually active men to test for HIV. The campaign need was identified in response to unique health and community issues presented by Aboriginal gay men.

Methods Campaign strategic development involved a series of quantitative research projects, using in-depth interviews and small focus groups with Aboriginal gay and other homosexually active men.

Results Initial quantitative research found:

- identity was complex and varied considerably for individuals, is dependent on context and is layered between sexual and ethnic identities;

- considerable concerned about the confidentiality of HIV testing services and the cost testing;

- HIV testing education programs need a sophisticated approach to targeting Aboriginal gay men and not necessarily relying on Aboriginal representation.

The final round of quantitative research found that:

- Confidentiality was seen as the most important theme. Aboriginal gay men were highly concerned about being discrete and anonymous;

- Cost also emerged a key barrier to testing, with a need to be assured that HIV testing would be cost free; and

- Aboriginal gay men also rejected the notion that HIV testing education materials should necessarily be tailored. While there was an acknowledgment that there was a place for targeted prevention education materials for Aboriginal people, it was also considered that a HIV testing materials should not single out and therefore potentially alienate the Aboriginal gay men.

Conclusion Developing and delivering HIV Testing education materials to Aboriginal Gay men presents complex challenge to HIV educators. A relatively small and highly mobile community, lower health literacy and issues of shame mean HIV Testing education materials need to consider a range of different strategies, including targeting materials specifically to meet the needs identified by Aboriginal gay men.

Disclosure of interest statement The ACON is funded by the NSW Ministry of Health. No pharmaceutical grants were received in the development of this study.

\section{P01.04 WITHDRAWN}

\section{P01.05 EQUITY IN ABORIGINAL HIV HEALTH CARE DELIVERS THE GOODS}

MT Gilles*, R McGuckin, J Ward, M Edel, Lyn Symonds, Gloria Jones, Chris Hall, P Smith. Western Australian Country Health Service

\subsection{6/sextrans-2015-052270.215}

Introduction Confusion exists with regard to the delivery of equal or equitable services. Far from providing the same care to all our clients we have delivered an enhanced, culturally secure service to a small cohort of Aboriginal people living with HIV. This paper evaluates the impact of this program. Our hypothesis is that this model of care results in improved outcomes. This paper seeks to present this model of HIV care and outline the results as a consequence of this care.

Methods Data were collected with regard to the type and number of occasions of service, medication compliance, HIV viral loads, CD4 counts, mortality and pregnancy outcomes.

Results From 1994 primary care was provided to the cohort by four doctors, demonstrating low staff turnover for a regional 